Research Article

\title{
Knowledge and Practices of Unani Medicine among Patients Attending OPD at a Tertiary Care Hospital in North India
}

\author{
Tamanna Nazli', Jugal Kishore ${ }^{2}$, Syed Ahmad Khan ${ }^{3}$, Heena $^{4}$, Abdul Raheem $^{5}$, Asim Ali Khan $^{6}$
}

${ }^{1}$ Research Officer, Unani Medical Centre, VMMC \& Safdarjung Hospital, New Delhi, India.

${ }^{2}$ Director Professor \& Head of Department-Community Medicine, VMMC \& Safdarjung Hospital, New Delhi, India.

${ }^{3}$ Research Officer, Scientist-4, Unani Medical Centre, Safdarjung Hospital, New Delhi, India.

${ }^{4}$ Statistician, VMMC \& Safdarjung Hospital, New Delhi, India.

${ }^{5}$ Research Officer, Scientist-4, Central Council for Research in Unani Medicine, Headquarters, New Delhi, India.

${ }^{6}$ Director General, CCRUM, Central Council for Research in Unani Medicine, MoAYUSH, Govt. of India, New Delhi, India.

DOI: https://doi.org/10.24321/2455.9199.202002

I $\quad \begin{array}{lllll}\mathbf{N} & \mathbf{F} & \mathbf{O}\end{array}$

Corresponding Author:

Tamanna Nazli, Unani Medical Centre, VMMC \&

Safdarjung Hospital, New Delhi, India.

E-mail Id:

tamanna.ccrum@gmail.com

Orcid Id:

https://orcid.org/0000-0003-4517-3485

How to cite this article:

Nazli T, Kishore J, Khan SA, Heena, Raheem A, Khan AA. Knowledge and Practices of Unani Medicine among Patients Attending OPD at a Tertiary Care Hospital in North India. Int J HealthCare Edu \& Med Inform 2020; 7(1\&2): 10-15.

Date of Submission: $2020-8-25$

Date of Acceptance: 2020-10-22
$\begin{array}{llllllll}\mathbf{A} & \mathbf{B} & \mathbf{S} & \mathbf{T} & \mathbf{R} & \mathbf{A} & \mathbf{C} & \mathbf{T}\end{array}$

Introduction: Unani medicine is one of the most commonly practiced form of traditional system of medicines in India. There is dearth of published data showing the knowledge and practices of general population about Unani treatment modality.

Objectives: To evaluate the knowledge and practices and to determine factors associated with the use of Unani medicine in participants attending Unani Out Patient Department, at a tertiary care hospital.

Materials and Methods: A hospital based cross-sectional observational study was conducted in a tertiary care hospital to assess the knowledge and practices of Unani system of medicine among 365 participants attending the out-patient department between July 2019 to September 2019.

Result: Out of 365 subjects $51 \%$ were males and $49 \%$ were females with mean age $40.15 \pm 14.62$ years, ranged between 16 to 90 years of age. Of the 365 participants, majority of patients were aware of Unani medicine, $75.1 \%$ of the patients came to know about Unani Medicine from sources such as family, friends and neighbours and $73.9 \%$ believed that Unani medicine is effective. Although their practices of Unani medicine were limited.

Conclusion: OPD attenders had very good awareness about Unani medicine, however, limited practices were observed among them. Therefore, promotion of Unani healthcare through evidence-based practices is required for better acceptability among people.

Keywords: Traditional Medicine, Alternative Medicine, AYUSH, Unani, Temperament 


\section{Introduction}

Traditional Medicine (TM) system has a long history for the maintenance of health as well as in the diagnosis, prevention or treatment of diseases based on practices on the theories, beliefs and experience indigenous to different cultures. This knowledge has generally been passed down by word of mouth from generation to generation, described in ancient classical and other literature, often inaccessible to the common man. Documentation of this existing knowledge has become imperative to safeguard the sovereignty of this knowledge and to protect it from being misused.

The use of herbal medicinal products and supplements has increased tremendously over the past three decades with not less than $80 \%$ of people worldwide relying on them. ${ }^{1}$ India has recognized indigenous system of medicine viz., Ayurveda, Unani, Siddha, Homeopathy, Yoga and Naturopathy and here they have been given an independent identity under the AYUSH ministry. Moreover, WHO Traditional Medicine Strategy 2014-2023 was developed and launched in response to the World Health Assembly resolution on traditional medicine, the strategy aims to support Member States in developing proactive policies and implementing action plans that will strengthen the role traditional medicine plays in keeping populations healthy, promoting safe and effective use of T\&CM through the regulation, evaluation and integration of T\&CM products, practices and practitioners into health systems. ${ }^{2}$ India has a unique position in the world where herbal drugs are popular among rural and urban communities but often underestimated part of health services due issues regarding its safety, effectiveness, quality, availability, preservation and regulation which need to be addressed. The present study was carried out to assess the awareness and attitude about the Unani system of medicine among patients visiting newly opened Unani Medical Centre at Safdarjung Hospital.

\section{Materials and Methods}

\section{Study Design, Setting and Period}

A hospital-based cross-sectional observational study was conducted in a tertiary care hospital from July 2019 to September 2019 to assess the Knowledge, and Practices regarding Unani medicine. Respondents were patients of 16 years and above, of either sex attending the Out Patient Department (OPD) for Unani treatment during the study period. The daily OPD footfall ranges between $60-80$ per day, and participants were selected based on convenience sampling technique, every $10^{\text {th }}$ patient attending the clinic for routine visits seeking Unani treatment was randomly selected for the interview. Informed verbal consent was obtained from each patient. Their demographic characteristics including gender, age, marital status, education status, employment status, and smoking status were recorded.

\section{Data Collection Tools and Processes}

Data collection was conducted through individual face to face interviews by trained data collectors using a pretested structured interviewer-administered questionnaire. The questionnaire was short and simple consisted of 17 items with appropriate options which included multiple choice and close-ended understandable questions. The data collection took 10 to 12 minutes to complete which was segmented into four sections; the first section collected socio-demographic characteristics including gender, age, marital status, education status, employment status, religion, dietary detail, alcohol use and smoking status were recorded. The second section consisted patients' vital statistics viz. pulse rate, blood pressure, height and weight. The third section comprising 7 questions focusing individuals' knowledge, awareness and attitude towards Unani medicine by asking questions about individuals' awareness about Unani system of medicine and the last section consisted of 10 questions ascertaining individual's temperament (mizaj) as per Unani fundamentals. The objectives were duly explained to each and every selected participant and doubts, if any, were clarified before the questions were asked. The respondents were informed verbally about the purpose of the study and their verbal consent was taken to participate in the survey. Subsequently, patients were clinically examined for vitals, and questions were asked as per the questionnaire. Inclusion criteria for the survey included all patients of either sex with age more than 16 years attending the OPD of Unani Medical Centre at Safdarjung Hospital.

Permission was obtained from the Director General of the Central Council for Research in Unani Medicine and participants were assured of the confidentiality of the details collected.

\section{Statistical Analysis}

After collection of data it was double entered in Microsoft Excel Sheet and validated. A clean database was generated and analysed in SPSS (version 23). Data was presented by using frequency tables. To find out the association between categorical variables Chi-square test was used, p-value less than 0.05 was considered as statistically significant.

\section{Result}

The demographic details are summarized in Table 1. Among 365 respondents, 51\% were males and $49 \%$ were females with male to female ratio of 1:1, the mean age of respondents was $40.24 \pm 14.45$ years ranged from 16 to 90 years, the majority (32.6\%) of them were in the age group ranged between $31-45$ and $16-30$ years (32.1\%). Overall, $73.4 \%$ of all respondents were married, large majority (56.7\%) of the respondents were Hindu, $36.4 \%$ were Muslims, while those following other religion were very 
few, nearly 2.2\% were Christians, $2.5 \%$ were Sikhs, and $2.2 \%$ were followers of Buddhism. Education is one of the most important variables of survey that might affect the person's attitudes and the way of understanding the perception towards health. Most of the individuals were educated, literacy level of the respondents was reasonably good with majority (35.6\%) having education up to graduates or post-graduate level and merely $7.7 \%$ of them were illiterate. The total mean score of SES calculated as per Kuppuswamy scale by adding up all the three scores, namely, education, occupation, and total family income was $14.15 \pm 6.11$ and the majority of the patients (37.5\%) belonged to upper middle-class of Socio-economic status.

Table I.Frequency of socio-demographic characteristics and temperament of the participants $(N=365)$

\begin{tabular}{|c|c|}
\hline Variable & $\begin{array}{l}\text { Frequency } \\
\text { n (\%) }\end{array}$ \\
\hline Age (in years) Mean $\pm S D$ & $40.24 \pm 14.45$ \\
\hline \multicolumn{2}{|l|}{ Gender n (\%) } \\
\hline Male & $186(51)$ \\
\hline Female & $179(49)$ \\
\hline BMI (kg/m2) (Mean $\pm S D)$ & $25.43 \pm 5.00$ \\
\hline \multicolumn{2}{|l|}{ Blood pressure (Mean \pm SD) } \\
\hline Systolic & $121.26 \pm 17.12$ \\
\hline Diastolic & $80.53 \pm 11.07$ \\
\hline Socioeconomic status (Mean \pm SD) & $14.15 \pm 6.11$ \\
\hline \multicolumn{2}{|l|}{ Educational Status n (\%) } \\
\hline Illiterate & $28(7.7)$ \\
\hline $\begin{array}{l}\text { Primary/middle/High/ Intermediate/ } \\
\text { Post high school diploma }\end{array}$ & $194(53.2)$ \\
\hline Graduate and above & $143(39.2)$ \\
\hline \multicolumn{2}{|l|}{ Marital Status n (\%) } \\
\hline Married & $268(73.4)$ \\
\hline Separated & $2(0.5)$ \\
\hline Single & $81(22.2)$ \\
\hline Widow or widower & $14(3.8)$ \\
\hline \multicolumn{2}{|l|}{ Religion n (\%) } \\
\hline Buddhism & $8(2.2)$ \\
\hline Christian & $8(2.2)$ \\
\hline Hindu & $207(56.7)$ \\
\hline Muslim & $133(36.4)$ \\
\hline Sikh & $9(2.5)$ \\
\hline \multicolumn{2}{|l|}{ Temperament/ Mizaj (Mean \pm SD) } \\
\hline Sanguine (Damvi) & $4.41 \pm 1.63$ \\
\hline Phlegmatic (Balghami) & $1.67 \pm 1.15$ \\
\hline
\end{tabular}

\begin{tabular}{|c|c|}
\hline Bilious (Safrawi) & $2.99 \pm 1.46$ \\
\hline Melancholic (Sawdavi) & $0.93 \pm 1.02$ \\
\hline Smoking status $\mathbf{n}(\%)$ & \\
\hline Non-smoker & $306(83.8)$ \\
\hline Ex- smoker & $36(9.9)$ \\
\hline Smokers & $23(6.3)$ \\
\hline Alcohol users $\mathbf{n}(\%)$ & \\
\hline Never & $300(82.2)$ \\
\hline Quit & $16(4.4)$ \\
\hline Seldom & $37(10.1)$ \\
\hline Often & $12(3.3)$ \\
\hline
\end{tabular}

The temperament (mizaj) of the subjects was assessed on parameters of Ajnas-e-Ashra (ten criteria of assessment) in all the respondents, we observed that mean of the Sanguine temperament (Damvi) is higher $(4.41 \pm 1.63)$, followed by Bilious (Safrawi) (2.99 \pm 1.46$)$, Phlegmatic (Balghami) $(1.67 \pm 1.15)$ and Melancholic (Sawdavi) $(0.93 \pm 1.02)$ temperament (Table 1).

\section{Knowledge}

To find out the awareness level among respondents this survey was carried out. Of the 365 participants, almost all of patients were aware of Unani medicine. It was noted that nearly three quarter $(n=274,75.1 \%)$ of the patients came to know about Unani Medicine from sources such as family, friends and neighbours followed by posters and printed material (6.6\%) and newspaper and magazines (6.6\%), internet (4.7\%), television (TV)/radio(4.4\%), brochures, public lectures/ community health meeting (2.2\%) and least from the community health workers $(0.5 \%)$ (Figure 1 ).

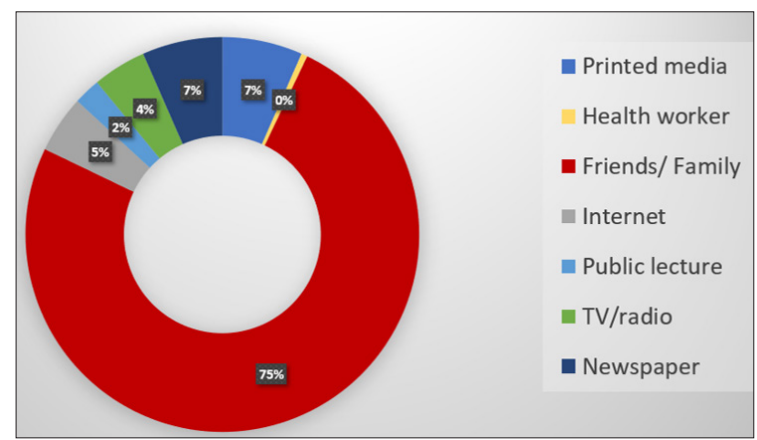

Figure I. Source of information about Unani system of medicine

\section{Practices}

It is evident that when respondents who took Unani treatment earlier when asked about the past experience, most of the respondents $25.6 \%$ got cured, $20.8 \%$ respondent were very much satisfied and $41.6 \%$ respondent were 
satisfied with the Unani treatment. However, very few of the respondents have stated no effect (12\%) after the Unani therapy (Table 2).

Table 2.Knowledge and practice of the participants regarding Unani medications $(\mathbf{N}=365)$

\begin{tabular}{|c|c|}
\hline Variables & $\begin{array}{l}\text { Frequency } \\
\text { n (\%) }\end{array}$ \\
\hline \multicolumn{2}{|l|}{ Knowledge } \\
\hline Have you heard of Unani medicine? & $365(100)$ \\
\hline \multicolumn{2}{|l|}{$\begin{array}{l}\text { Do you know about any Govt. Unani } \\
\text { hospital/ dispensary nearby? }\end{array}$} \\
\hline No & $229(62.7)$ \\
\hline Yes & $136(37.3)$ \\
\hline \multicolumn{2}{|l|}{$\begin{array}{l}\text { Do you believe that Unani medicines are } \\
\text { safe? }\end{array}$} \\
\hline Yes & 85 (73.9) \\
\hline Other reasons & $30(26.1)$ \\
\hline Not applicable & $240(65.8)$ \\
\hline \multicolumn{2}{|l|}{ Practice } \\
\hline \multicolumn{2}{|l|}{$\begin{array}{l}\text { Have you taken Unani medicines or } \\
\text { treatment before }\end{array}$} \\
\hline No & $240(65.8)$ \\
\hline Yes & $125(34.2)$ \\
\hline \multicolumn{2}{|l|}{$\begin{array}{l}\text { What was your experience with Unani } \\
\text { treatment? [ } n=125]\end{array}$} \\
\hline Got cured & $32(25.6)$ \\
\hline No-effect & $15(12)$ \\
\hline Satisfied & $52(41.6)$ \\
\hline Very much satisfied & $26(20.8)$ \\
\hline \multicolumn{2}{|l|}{$\begin{array}{l}\text { Why do you think Unani is a better treat- } \\
\text { ment option? [ } n=115 / 125]\end{array}$} \\
\hline Cure root cause & $13(11.3)$ \\
\hline Effective & $13(11.3)$ \\
\hline No side effect & $85(73.9)$ \\
\hline Palatable & $4(3.5)$ \\
\hline \multicolumn{2}{|l|}{$\begin{array}{l}\text { When you fall ill, whom you consult first } \\
\text { for treatment? }\end{array}$} \\
\hline Allopathic & $321(87.9)$ \\
\hline Ayurveda & $12(3.3)$ \\
\hline Homeopathy & $8(2.2)$ \\
\hline Unani & $24(6.6)$ \\
\hline $\begin{array}{l}\text { Whether Unani is your first line of treat- } \\
\text { ment? }\end{array}$ & \\
\hline
\end{tabular}

\begin{tabular}{|c|c|}
\hline No & $341(93.4)$ \\
\hline Yes & $24(6.6)$ \\
\hline
\end{tabular}

In the survey, of the 125 (34.2\%) patients who had Unani treatment before, the response to treatment was quite satisfactory in respondents. When asked that why do you think Unani is better alternative treatment of choice for treating diseases, majority of the respondents $73.9 \%$ believed that the Unani medicines are comparatively safer and has no or negligible side effects, $11.3 \%$ respondents thought it is an effective treatment method, $11.3 \%$ believed that it's approach of treating the root cause of the diseases Table 2.

However, Allopathy was the preferred choice of treatment in majority (87.9\%) of respondents and among alternate system of medicine only $6.6 \%$ have Unani, $3.3 \%$ Ayurvedic treatment and 2.2\% Homeopathic treatment (Table 2). However, among the surveyed respondents ( $n=365), 34.2 \%$ preferred Unani Medication in number of diseases such as Musculo-skeletal or Joints related problems (29.6\%) which mainly include osteoarthritis, rheumatoid arthritis, gout, cervical neck pain, frozen shoulder, sciatica, back pain, Gastro-intestinal disorders (25.8\%), Dermatological disorders specially vitiligo, psoriasis, and fungal infections (21.1\%), Respiratory problems (16.2\%); male sexual problems $(10.7 \%)$, female diseases (10.1\%) lifestyle disorders/ Non-Communicable Diseases (NCD); Obesity, Hypertension, Diabetes mellitus, cardiovascular diseases (7.7\%) (Figure 2).

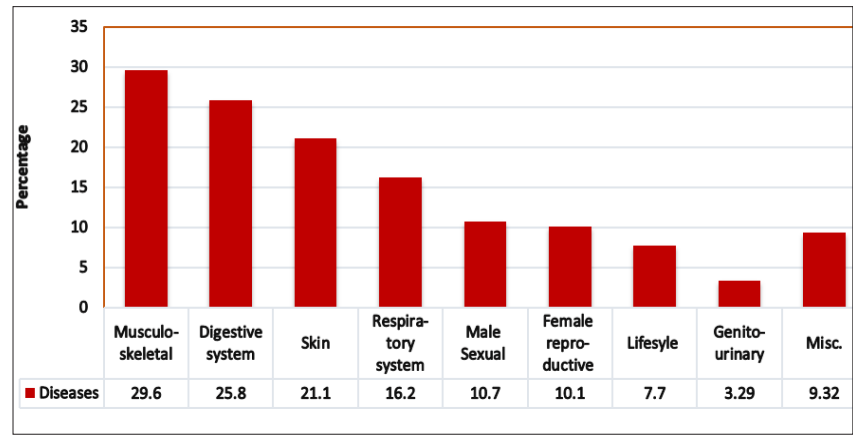

Figure 2.Percentage of Diseases in which respondents desired Unani treatment

Demographic characteristics, knowledge, attitude and practices of the participants $(n=365)$ were correlated with use of Unani Medicine (UM). In demographic characteristics only gender showed significant association to the use of UM ( $p<0.001 ;$ OR 2.135; $\mathrm{Cl} 1.37,3.327)$ and in religion Muslim significantly more users of Unani and Hindu were less users. $(p=0.001)$. No other significant difference was found in relation to use of Unani treatment (Table 3). 
Table 3.Relationship of participants characteristics with usage of Unani medicines $(\mathbf{N}=365)$

\begin{tabular}{|c|c|c|c|c|}
\hline \multirow{2}{*}{ Variables } & \multicolumn{2}{|c|}{ Unani medicines users n (\%) } & \multirow{2}{*}{$\chi 2$ Value } & \multirow{2}{*}{ p-value } \\
\hline & Yes $(n=125)$ & No $(n=240)$ & & \\
\hline \multicolumn{5}{|l|}{ Age (in years) } \\
\hline$\leq 40(n=191)$ & $58(30.4)$ & $133(69.6)$ & \multirow{2}{*}{2.679} & \multirow{2}{*}{0.102} \\
\hline$>40(n=174)$ & $67(38.5)$ & $107(61.5)$ & & \\
\hline \multicolumn{5}{|l|}{ Gender } \\
\hline Female $(n=179)$ & $46(25.7)$ & $133(74.3)$ & \multirow{2}{*}{11.399} & \multirow{2}{*}{0.001} \\
\hline Male $(n=186)$ & $79(42.5)$ & $107(57.5)$ & & \\
\hline \multicolumn{5}{|l|}{ Education } \\
\hline Illiterate $(n=28)$ & $8(28.6)$ & $20(71.4)$ & \multirow{2}{*}{0.434} & \multirow{2}{*}{0.51} \\
\hline Educated $(n=337)$ & $117(34.7)$ & $220(65.3)$ & & \\
\hline \multicolumn{5}{|l|}{ Socioeconomic Status } \\
\hline Lower Class ( $n=4)$ & $1(25)$ & $3(75)$ & 0.154 & 0.695 \\
\hline Lower middle class $(n=115)$ & $45(39.1)$ & $70(60.9)$ & 1.778 & 0.182 \\
\hline Upper class $(\mathrm{n}=17)$ & $9(52.9)$ & $8(47.1)$ & 2.767 & 0.096 \\
\hline Upper lower class ( $n=92)$ & $31(33.7)$ & $61(66.3)$ & 0.017 & 0.898 \\
\hline Upper middle class ( $n=137)$ & $39(28.5)$ & $98(71.5)$ & 3.253 & 0.071 \\
\hline \multicolumn{5}{|l|}{ Religion } \\
\hline Hindu (n=207) & $38(18.4)$ & $169(81.6)$ & 53.613 & 0.001 \\
\hline Muslim (n=133) & $81(60.9)$ & $52(39.1)$ & 66.024 & 0.001 \\
\hline Others $(n=25)$ & $6(24.0)$ & $19(76.0)$ & 1.251 & 0.263 \\
\hline \multicolumn{5}{|l|}{ Source } \\
\hline Family, friends and neighbours $(n=274)$ & $89(32.5)$ & $185(67.5)$ & \multirow{2}{*}{1.52} & \multirow{2}{*}{0.218} \\
\hline Others $(n=91)$ & $36(39.6)$ & $55(60.4)$ & & \\
\hline
\end{tabular}

\section{Discussion}

In the present study, awareness level of respondents was very good, almost all patients knew about Unani Medicine (UM) and friends, family members and colleagues were the common source of information of UM which is consistent with previous studies. ${ }^{3-7}$ The study conducted by National Sample Survey Organization's Report covering all parts of Indian subcontinent, less than $30 \%$ of the respondents have reported use of AYUSH medicines. ${ }^{6}$ Therefore, there is need to improve the awareness about the AYUSH systems. The age group of 16-45 years formed the largest proportion of the study respondents. This is consistent with many other studies done earlier. ${ }^{3,5,8}$

In the present study only $34.2 \%$ of the respondents reported use of Unani treatment which is actually less, if we compare a study done by Imran et al (74\%) and Raheem et al (41.78\%). . $^{5}$

Allopathic medicine was the most preferred mode of treatment in majority of the respondents (87.9\%) which is consistent with earlier study in which $72.88 \%$ of the consumers preferred Allopathic medicines over traditional medicine. ${ }^{5,9,10}$ Although, only few $(n=24,6.6 \%)$ of them preferred Unani medicine as mode of treatment. The respondents ( $n=125 / 365$ ) later asked question regarding the use of Unani medicine as a better healthcare option, 115 of them responded positively by giving reasons that it safe or negligible side effects (73.9\%), effective (11.3\%), cure from root (11.3\%) and palatable (3.5\%). These findings are consistent with previous studies where $62.8 \%$ and $69.82 \%$ respondents thought that Unani medicine has negligible side effect. ${ }^{5,9} \mathrm{~A}$ study from Dhaka observed that people are turning to Unani because of serious side effects due to modern medicine and lack of effectiveness in many chronic ailments. ${ }^{8}$

The outcome of the Unani treatment in these respondents was quite satisfactory, $25.6 \%$ got cured completely, $20.8 \%$ were very much satisfied and $41.6 \%$ were satisfied only a small number had no effect (12\%). Unani medicine was majorly used in the present study for the treatment of 
Musculo-skeletal problems (29.6\%) which mainly include osteo-arthritis, rheumatoid arthritis, gout, cervical neck pain, frozen shoulder, sciatica, back pain etc., Gastrointestinal disorders (25.8\%), and Dermatological disorders (21.1\%).

The limitations of the study: The sample was from the tertiary healthcare setting of Delhi, and thus the results may not be generalizable to other Hospitals or communities in India. Furthermore, it included all patient characteristics on one instance only and did not follow the patients over time to study the actual effects of UM on their disease status and overall health therefore, we do not have information on the actual change in knowledge and attitudes of any specific cohort of patients over time.

\section{Conclusion}

Knowledge and practices of people about Unani medicine was good and most of the information about Unani medicine was from family members and friends. People have belief that Unani medicine is safe that could be the reason of its use for many chronic disorders. This study encourages to promote Unani medicine further for the benefit of people.

\section{Conflict of Interest: None}

\section{References}

1. Ekor M. The growing use of herbal medicines: issues relating to adverse reactions and challenges in monitoring safety. Front Pharmacol 2014; 4: 177. Published 2014 Jan 10. DOI:10.3389/fphar.2013.00177

2. WHO traditional medicine strategy: 2014-2023. Available from: https://www.who.int/medicines/ publications/traditional/trm_strategy14_23/en/ Accessed 16th August 2020].

3. Shashikumar BM, Sheethal MP. Knowledge, Attitude and Practices Regarding AYUSH Among The Allopathic Doctors In Mandya District. NatI J Integr Res Med 2015; 6(4): 68-71.

4. Wani P, Siddiqui MJ, Zaheer MT, Ahmad S. A study to assess the knowledge attitude and practices of the Unani Medicine in the new comers of A \& U Tibbia College. Elixir Human Physio 2014; (66): 20700-20704.

5. Raheem A, Nazli T, Kishore J, Heena, Kazmi MH et al. Perception and Practices of People about Unani Medicine attending National Arogya Fair, Visakhapatnam, Andhra Pradesh. J Adv Res in Ayurveda, Yoga, Unani, Sidhha \& Homeopathy 2020; 7(1\&2): 1-9.

6. Srinivasan R, Sugumar VR. Spread of Traditional Medicines in India: Results of National Sample Survey Organization's Perception Survey on Use of AYUSH. Journal of Evidence-Based Complementary \& Alternative Medicine 2017; 22(2): 194-204. https:// doi.org/10.1177/2156587215607673

7. Gari A, Yarlagadda R, Wolde-Mariam M. Knowledge, attitude, practice, and management of traditional medicine among people of Burka Jato Kebele, West Ethiopia. J Pharm Bio allied Sci 2015; 7(2): 136-144. DOI:10.4103/0975-7406.148782:10.4103/09757406.148782 .

8. Siddika R, Nyeem M, Nowrose M, Meher, Mannan, MA. Awareness on Unani medicine among the urban community people in Dhaka city. International Journal of Advanced Educational Research 2017; 2(3): 66-71.

9. Imran M, Amir M, Naqvi H, Naaz S. The prevalence and patterns of usage of Ayurveda, Unani and home remedies in younger adults of rural North India. International Journal of Green Pharmacy 2017; 11(2): 108.

10. Katole H. Reasons of Customer Preference towards Allopathy versus Ayurvedic therapy. International Journal of Research in Pharmaceutical Sciences 2020. From: https://pharmascope.org/ijrps/article/view/ 1941/3250\#citations. 